\title{
Late-onset thyrotoxicosis after the cessation of amiodarone $\mathrm{e}^{\text {tr }}$
}

\author{
Melissa E. Middeldorp a, b, Adrian D. Elliott ${ }^{\mathrm{a}, \mathrm{b}}$, Celine Gallagher ${ }^{\mathrm{a}, \mathrm{b}}$, Dominik Linz ${ }^{\mathrm{a}, \mathrm{b}}$, \\ Jeroen M.L. Hendriks ${ }^{\text {a, b }}$, Rajiv Mahajan ${ }^{\text {a, b }}$, Dennis H. Lau ${ }^{\text {a, b }}$, Prashanthan Sanders ${ }^{\text {a, b, * }}$ \\ a Centre for Heart Rhythm Disorders (CHRD), University of Adelaide, Australia \\ ${ }^{\mathrm{b}}$ Department of Cardiology, Royal Adelaide Hospital, Adelaide, Australia
}

\section{A R T I C L E I N F O}

\section{Article history:}

Received 2 March 2020

Received in revised form 19 July 2020

Accepted 30 July 2020

Available online 1 August 2020

\section{Keywords:}

\section{Amiodarone}

Thyrotoxicosis

Atrial fibrillation

Ventricular arrhythmia

Drug toxicity

\begin{abstract}
A B S T R A C T
Introduction: Amiodarone is a highly effective antiarrhythmic-drug with well recognized toxic sideeffects. The effects of the drug late in patients with atrial fibrillation (AF) is not well described. Methods and results: We present a single centre prospectively collected series of patients with thyrotoxicosis occurring late after the cessation of amiodarone. Between 2006 and 2018, 8 patients were identified with amiodarone induced thyrotoxicosis (AIT). Amiodarone was prescribed for AF in 7 patients and ventricular tachycardia in 1 patient. Mean duration of therapy was 329 [42-1092] days, mean dose of $200 \pm 103.5 \mathrm{mg} /$ day. Amiodarone use was short term ( $<140$ days $)$ in 4 of the 8 cases, with one treated for 42 days. Patients presented with symptoms including weight loss, tremors, palpitations, AF, sweats all indicative of AIT at a median of 347 [60-967] days post cessation. Thyroid function testing confirmed suppressed thyroid stimulating hormone and elevated T levels in all patients. Nuclear thyroid imaging in all cases demonstrated low uptake of iodine indicative of Type II AIT. All patients recovered following pharmaceutical treatment with Carbimazole and Prednisolone.

Conclusions: We describe a series of patients with late thyrotoxicosis after exposure to amiodarone. Our findings highlight the need for a high-index of clinical suspicion for AIT regardless of treatment duration or time after cessation of amiodarone.

Copyright $\odot$ 2020, Indian Heart Rhythm Society. Production and hosting by Elsevier B.V. This is an open access article under the CC BY-NC-ND license (http://creativecommons.org/licenses/by-nc-nd/4.0/).
\end{abstract}

\section{Introduction}

Amiodarone is a highly effective antiarrhythmic drug commonly used in the treatment of ventricular arrhythmias and atrial fibrillation (AF). However, the toxicity of amiodarone is extensive with a myriad of potential organ damage including the liver, lungs, cornea, skin, and thyroid gland. Specifically, these adverse effects have been shown to occur at various time points during amiodarone use with thyroid dysfunction seen in $15-20 \%$ of patients treated [1]. Furthermore, several isolated cases of thyroid dysfunction have been reported to occur following cessation of amiodarone [2,3]. Here, we present a single centre case series of 8 patients with amiodarone induced thyrotoxicosis (AIT) occurring late following ceasing the drug.

\footnotetext{
This case series was awarded highest scoring abstract award - Allied professional category, heart rhythm society congress 2013

* Corresponding author. Centre for Heart Rhythm Disorders, Department of Cardiology, Royal Adelaide Hospital, Port Road, Adelaide, SA, 5000, Australia.

E-mail address: prash.sanders@adelaide.edu.au (P. Sanders).

Peer review under responsibility of Indian Heart Rhythm Society.
}

\section{Methods}

This is a single centre case series of amiodarone induced thyrotoxicosis were prospectively collected between 1st January 2006 and 30th June 2018. Over this time period those who were prescribed amiodarone were followed to assess complications that may arise. Any patient who presented with symptoms of thyrotoxicosis as a result from exposure with Amiodarone were collected and included for analysis. Upon diagnosis, all patients were referred to an endocrinologist for treatment and management with data from this collected. All patients underwent thyroid function testing, and nuclear thyroid imaging. Baseline data was collected and follow up of the patients was undertaken to assess complications, management and progress. This case series was approved by the institutional Human Research Ethics Committee.

\section{Results}

In this single centre cohort a total of 386 patients were prescribed amiodarone of which $8(2.1 \%)$ presented with amiodarone induced thyrotoxicosis. The 8 patients comprised of 3 females and 5 
males with a mean age of $63 \pm 10$ years (Table 1 ). They were on amiodarone therapy for $\mathrm{AF}(\mathrm{n}=7)$ and ventricular tachycardia $(\mathrm{n}=1)$. Median duration of amiodarone therapy was 329 [42-1092] days at a mean dose of $200 \pm 103.5 \mathrm{mg}$ per day. Of note, amiodarone use was only short term ( $<140$ days) in 4 of the 8 cases, with one treated for only 42 days. All patients presented with symptoms indicative of thyrotoxicosis or symptomatic $\mathrm{AF}$ at a median of 347 [60-967] days post cessation of amiodarone. The three patients with symptomatic AF had previously undergone successful catheter ablation for AF with no arrhythmia recurrence until their presentation with thyrotoxicosis. The longest temporal gap between cessation of amiodarone and onset of thyrotoxicosis was almost 3 years. All patients underwent thyroid function testing with evidence of suppressed thyroid stimulating hormone (TSH) and elevated $\mathrm{T}_{3}$, and $\mathrm{T}_{4}$ levels (Table 1 ). Nuclear thyroid imaging in all 8 cases demonstrated low uptake of iodine in the thyroid gland indicative of Type II AIT (Fig. 1). One patient underwent thyroid doppler scan which demonstrated coarsened thyroid echotexture with normal vasculature. All patients were referred to an endocrinologist for further management. Patients were managed as per the guidelines [4] and were successfully treated with a combination of prednisolone and carbimazole; with 3 patients requiring long-term carbimazole, 1 patient required propylthiouracil following reaction to carbimazole. Notably, the three patients with recurrent $\mathrm{AF}$ became free from arrhythmia following achievement of euthyroid status. Here, we detailed two cases from our series.

The first case is a 54-year-old male with longstanding persistent AF and a previous history of hypertension and thromboembolic stroke. He was treated with 53 weeks of amiodarone prior to undergoing catheter ablation for AF. However, 349 days after having ceased amiodarone, he presented with classic symptoms of sweats, weight loss, diarrhoea, and poor sleep. His elevated thyroid hormone profile (Table 1, Patient 1) and low uptake of iodine from nuclear imaging confirmed the diagnosis of Type II AIT. He responded well to prednisolone and carbimazole therapy, his symptoms resolved, and he had complete normalisation of thyroid hormone profile.

The second case is a 45-year-old male initially presented with rapid ventricular flutter and was diagnosed with cardiac sarcoidosis with pulmonary involvement. He received an implantable cardioverter-defibrillator. Subsequently, he presented with ventricular tachycardia storm resulting in multiple shocks from his device. He was then commenced on a short course of amiodarone as a bridge to catheter ablation therapy. Interestingly, despite a relatively short exposure to amiodarone for only 12 weeks, he developed typical symptoms of thyrotoxicosis consisting of tremors, palpitations, sweats, bloating and a choking sensation at 967 days after cessation of therapy. Thyroid function testing (Table 1, Patient 3) and nuclear thyroid scan were indicative of Type II AIT. He was successfully treated with prednisolone and carbimazole and became euthyroid within 3 months, his symptoms improved.

All Patients were managed as per the guidelines and were successfully treated with a combination of prednisolone and carbimazole; with 3 patients requiring long-term carbimazole, 1 patient required propylthiouracil following reaction to carbimazole. The three patients with recurrent AF became free from arrhythmia following achievement of euthyroid status. No patients developed hypothyroidism following this.

\section{Discussion}

This case series highlight the extent of the thyroid toxicity of amiodarone whereby late-onset Type II AIT can occur long after therapy cessation and even with short-term usage. Amiodarone has a complex chemical structure with each molecule having 2 iodine atoms constituting $37 \%$ of its total mass [5,6]. It is estimated that $10 \%$ of the iodine content is released as free iodine into the circulation, equating to a significant load of 100-300 times of its recommended daily iodine intake [5-7]. Amiodarone is distributed amongst a variety of tissues including the adipose tissue, myocardium, liver, and lung. It has a very long half-life of up to 100 days, due predominantly to its storage in adipose tissue.

There are two known types of AIT. Type I AIT is due to an excess of iodine that results in the greater production of thyroid hormones and often occurs in patients who have underlying thyroid disorder

Table 1

Patient characteristics.

\begin{tabular}{|c|c|c|c|c|c|c|c|c|c|c|c|}
\hline Patient & Age & Sex & Diagnosis & $\begin{array}{l}\text { Average daily } \\
\text { amiodarone } \\
\text { dosage (mg) }\end{array}$ & $\begin{array}{l}\text { Total amiodarone } \\
\text { treatment } \\
\text { duration (weeks) }\end{array}$ & $\begin{array}{l}\text { Thyrotoxicosison set } \\
\text { post cessation of } \\
\text { amiodarone (days) }\end{array}$ & $\begin{array}{l}\text { Serum T4 } \\
(\mathrm{pmol} / \mathrm{L}) \\
{[\mathrm{N}: 10-25]}\end{array}$ & $\begin{array}{l}\text { Serum T3 } \\
(\mathrm{pmol} / \mathrm{L})[\mathrm{N}: \\
3.1-5.4]\end{array}$ & $\begin{array}{l}\text { Serum TSH } \\
(\mathrm{mIU} / \mathrm{L})[\mathrm{N}: \\
0.5-4]\end{array}$ & Presenting symptoms & Treatment \\
\hline 1 & 54 & M & $\mathrm{AF}$ & 200 & 53 & 349 & $>75$ & $>30$ & $<0.01$ & $\begin{array}{l}\text { Weight loss, poor } \\
\text { sleep, muscle } \\
\text { weakness, diarrhoea }\end{array}$ & $\begin{array}{l}\text { Carbimazole, } \\
\text { Prednisolone }\end{array}$ \\
\hline 2 & 67 & $\mathrm{~F}$ & $\mathrm{AF}$ & 200 & 20 & 329 & 22.2 & 8.6 & $<0.01$ & Symptomatic AF & $\begin{array}{l}\text { Carbimazole, } \\
\text { Prednisolone }\end{array}$ \\
\hline 3 & 45 & M & VT & 400 & 12 & 967 & 32 & 8.7 & $<0.01$ & $\begin{array}{l}\text { Tremors, bloating, } \\
\text { palpitations, sweats }\end{array}$ & $\begin{array}{l}\text { Carbimazole, } \\
\text { Prednisolone }\end{array}$ \\
\hline 4 & 72 & $\mathrm{~F}$ & $\mathrm{AF}$ & 400 & 6 & 175 & 23.3 & 5.4 & $<0.01$ & $\begin{array}{l}\text { Tremors, diarrhoea, } \\
\text { palpitations }\end{array}$ & $\begin{array}{l}\text { Carbimazole, } \\
\text { Prednisolone }\end{array}$ \\
\hline 5 & 71 & $\mathrm{~F}$ & $\mathrm{AF}$ & 400 & 12 & 180 & 20 & 5 & 0.02 & $\begin{array}{l}\text { Tremors, sweats, } \\
\text { tachycardia }\end{array}$ & $\begin{array}{l}\text { Prednisolone, } \\
\text { Carbimazole, } \\
\text { Propylthiouracil }\end{array}$ \\
\hline 6 & 68 & M & $\mathrm{AF}$ & 200 & 156 & 60 & $>75$ & 20.8 & 0.01 & $\begin{array}{l}\text { Weight loss, loss of } \\
\text { appetite }\end{array}$ & $\begin{array}{l}\text { Carbimazole, } \\
\text { Prednisolone }\end{array}$ \\
\hline 7 & 58 & $\mathrm{~F}$ & $\mathrm{AF}$ & 200 & 53 & 249 & 54 & 23.9 & $<0.01$ & Symptomatic AF & $\begin{array}{l}\text { Carbimazole, } \\
\text { Prednisolone }\end{array}$ \\
\hline 8 & 55 & $\mathrm{M}$ & $\mathrm{AF}$ & 200 & 78 & 469 & 82 & 27 & $<0.01$ & $\begin{array}{l}\text { Symptomatic AF, } \\
\text { tremor, weight loss, } \\
\text { poor sleep, aches }\end{array}$ & Carbimazole \\
\hline Mean & $67 \pm 10$ & - & - & $200 \pm 103.5$ & $47[6-156]$ & 347 [60-967] & $\begin{array}{l}38.9[20- \\
>75]\end{array}$ & $\begin{array}{l}14.2[5- \\
>30]\end{array}$ & $\begin{array}{l}0.015 \\
{[<0.01} \\
-0.02]\end{array}$ & - & - \\
\hline
\end{tabular}

M - male; F - female; AF - atrial fibrillation; VT - ventricular tachycardia. 

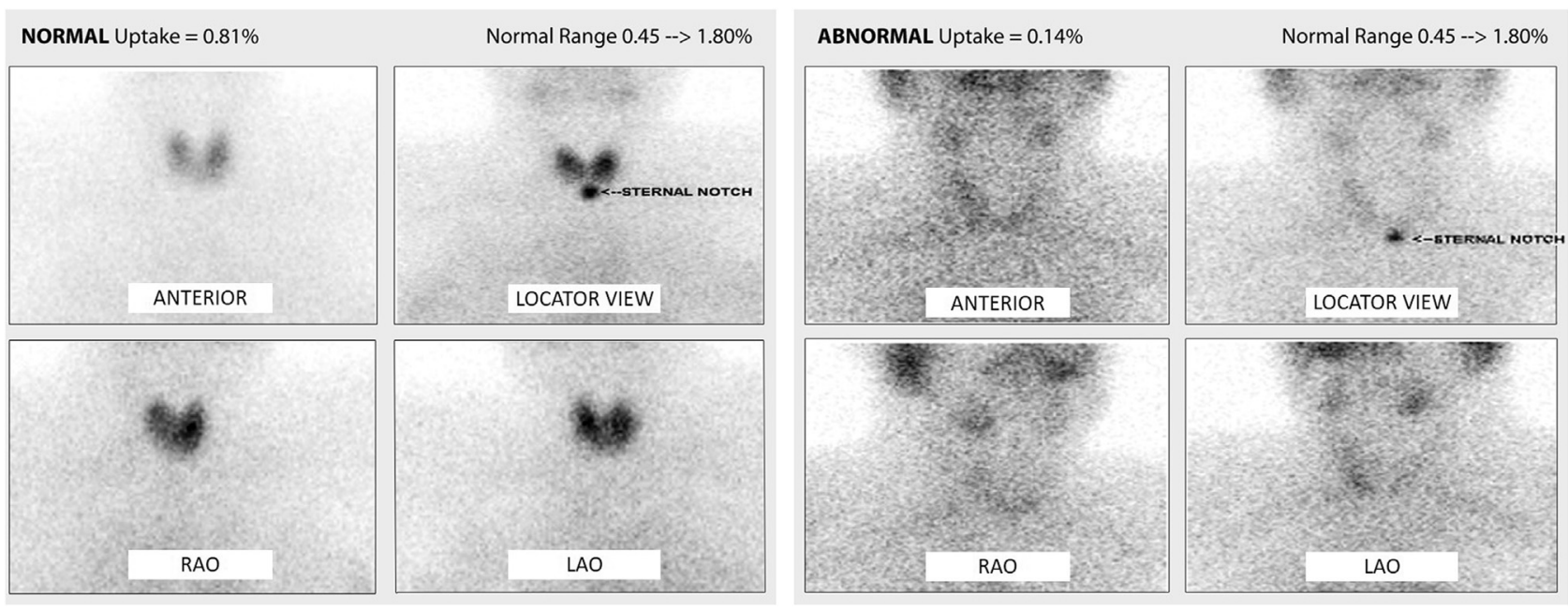

Fig. 1. NUCLEAR THYROID SCAN

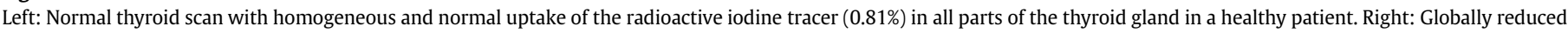

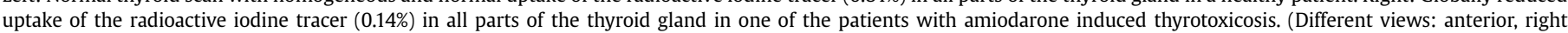
anterior oblique (RAO), left anterior oblique (LAO)).

such as Graves disease [8]. In Type I AIT, increased thyroid blood flow can be seen with Doppler sonography and increased radionucleotide uptake of iodine with nuclear scan [9]. By contrast, Type II AIT often occurs in patients with a normal thyroid $[2,5,6,8]$ and represents a destructive thyroiditis that releases pre-formed thyroid hormones due to local inflammation. Here, thyroid imaging will show decreased blood flow and low radionucleotide uptake of iodine. This inflammatory condition is highly responsive to steroid and thyroid suppressive therapies. Amiodarone toxicity has been reported previously in patients while on active amiodarone therapy $[2,6,10]$, in the current series however, we reported 8 cases of lateonset Type II AIT following cessation of amiodarone. Other thyroid toxicities such as amiodarone induced hypothyroidism and Type I AIT have been described both during active amiodarone use and months after its cessation [3,7]. Specifically, only a few isolated cases of AIT have been described late following the cessation of amiodarone although these cases appear to be mixed AIT and not classically Type II AIT [11,12].

\subsection{Clinical implications}

Guidelines from more than a decade ago suggest thyroid screening for patients receiving amiodarone at baseline and 6monthly thereafter with no recommendations for surveillance post drug cessation [13]. Our case series suggest that extended thyroid screening may be needed in conjunction with ongoing clinical vigilance for AIT in patients with previous exposure to amiodarone.

\section{Conclusions}

Delayed presentation of thyroid disorders in patients with previous exposure to amiodarone may not be uncommon. Our findings highlight the need for a high index of clinical suspicion for AIT regardless of treatment duration.

\section{Financial disclosures}

Drs Middeldorp and Gallagher are supported by a Postdoctoral Fellowships from the University of Adelaide. Dr Elliott is supported by an Early Career Fellowship from the National Heart Foundation of Australia (NHFA). Dr Linz is supported by a Beacon Fellowship from the University of Adelaide. Dr Hendriks is supported by the Derek Frewin Lectureship from the University of Adelaide and by a Fellowship from the NHFA. Dr Mahajan is supported by a Health Professional Fellowship co-funded by the National Health and Medical Research Council (NHMRC) and NHFA, and by the Leo J. Mahar Lectureship from the University of Adelaide. Dr Lau is supported by the Robert J. Craig Lectureship from the University of Adelaide. Dr Sanders are supported by Practitioner Fellowship from the NHMRC and by the NHF.

\section{Declaration of competing interest}

Dr Hendriks reports that the University of Adelaide has received on his behalf lecture and/or consulting fees from Medtronic and Pfizer/BMS. Dr Mahajan reports that the University of Adelaide has received on his behalf lecture fees and research funding from Medtronic and Abbott Medical. Dr Lau reports that the University of Adelaide has received on his behalf lecture and/or consulting fees from Abbott Medical, Boehringer Ingelheim, Bayer and Pfizer. Dr Sanders reports having served on the advisory board of BiosenseWebster, Boston Scientific, CathRx, Medtronic, and Abbott Medical. Dr Sanders reports that the University of Adelaide has received on his behalf lecture and/or consulting fees from Biosense-Webster, Medtronic, Boston-Scientific, Pfizer and Abbott Medical. Dr Sanders reports that the University of Adelaide has received on his behalf research funding from Medtronic, Abbott Medical, Boston Scientific, Biotronik and Liva Nova. All other authors have no disclosures.

\section{References}

[1] Bogazzi F, Tomisti L, Bartalena L, Aghini-Lombardi F, Martino E. Amiodarone and the thyroid: a 2012 update. J Endocrinol Invest 2012;35(3):340-8. https://doi.org/10.3275/8298.

[2] Daniels GH. Amiodarone-induced thyrotoxicosis. J.Clin. Endocrinol. Metabol. 2001;86(1):3-8. https://doi.org/10.1210/jcem.86.1.7119.

[3] Schreiber DH, DeFreest MS. Paroxysmal atrial fibrillation precipitated by amiodarone-induced thyrotoxicosis five months after cessation of therapy. J Emerg Med 2006;31(1):61-4. https://doi.org/10.1016/ j.jemermed.2005.08.011.

[4] Ross DS, Burch HB, Cooper DS, Greenlee MC, Laurberg P, Maia AL, et al. American thyroid association guidelines for diagnosis and management of hyperthyroidism and other causes of thyrotoxicosis. Thyroid 2016;26(10): 1343-421. https://doi.org/10.1089/thy.2016.0229. 2016.

[5] Basaria S, Cooper DS. Amiodarone and the thyroid. Am J Med 2005;118(7): 
706-14. https://doi.org/10.1016/j.amjmed.2004.11.028.

[6] Batcher EL, Tang XC, Singh BN, Singh SN, Reda DJ, Hershman JM, et al. Thyroid function abnormalities during amiodarone therapy for persistent atrial fibrillation. Am J Med 2007;120(10):880-5. https://doi.org/10.1016/ j.amjmed.2007.04.022.

[7] Padmanabhan H. Amiodarone and thyroid dysfunction. South Med J 2010;103(9):922-30. https://doi.org/10.1097/SMJ.0b013e3181e90500.

[8] Newman CM, Price A, Davies DW, Gray TA, Weetman AP. Amiodarone and the thyroid: a practical guide to the management of thyroid dysfunction induced by amiodarone therapy. Heart 1998;79(2):121-7.

[9] Bogazzi F, Bartalena L, Brogioni S, Mazzeo S, Vitti P, Burelli A, et al. Color flow Doppler sonography rapidly differentiates type I and type II amiodaroneinduced thyrotoxicosis. Thyroid 1997;7(4):541-5.

[10] Eskes SA, Endert E, Fliers E, Geskus RB, Dullaart RP, Links TP, et al. Treatment of amiodarone-induced thyrotoxicosis type 2: a randomized clinical trial. J.Clin. Endocrinol. Metabol. 2012;97(2):499-506. https://doi.org/10.1210/ jc.2011-2390.

[11] Kolesinska Z, Siuda K, Bobkowski W, Niedziela M. Amiodarone-induced thyrotoxicosis with paroxysmal supraventricular (ectopic atrial) tachycardia: case report and review of the literature. Arch Med Sci 2013;9(2):372-6. https://doi.org/10.5114/aoms.2012.32790.

[12] Kurt IH, Yigit T, Karademir BM. Atrial fibrillation due to late amiodaroneinduced thyrotoxicosis. Clin Drug Invest 2008;28(8):527-31.

[13] Goldschlager N, Epstein AE, Naccarelli G, Olshansky B, Singh B. Practical guidelines for clinicians who treat patients with amiodarone. Practice Guidelines Subcommittee. North Am. Soc.Pacing.Electrophysiol.Arch. Intern. Med. 2000;160(12):1741-8. 